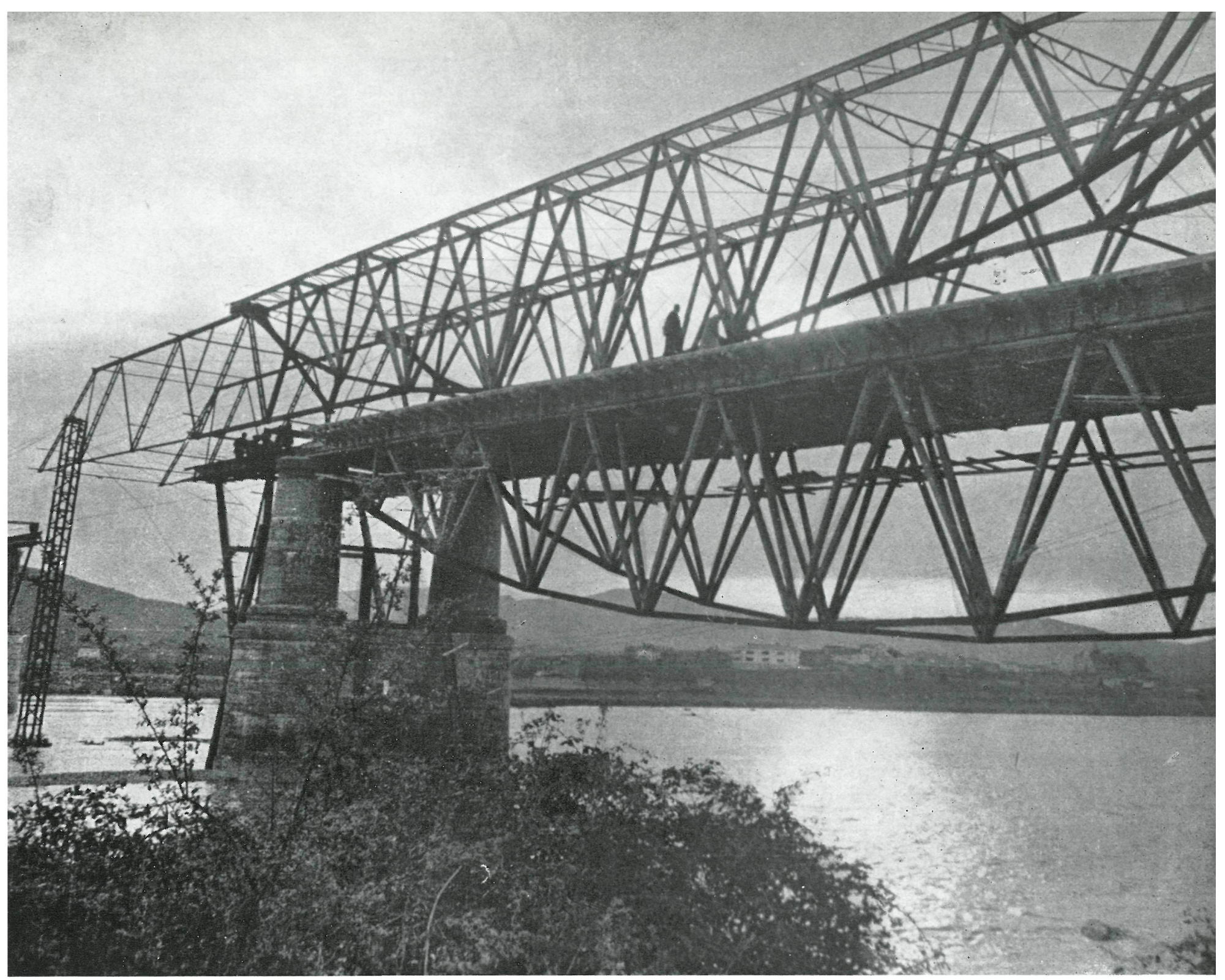

E. TORROJA

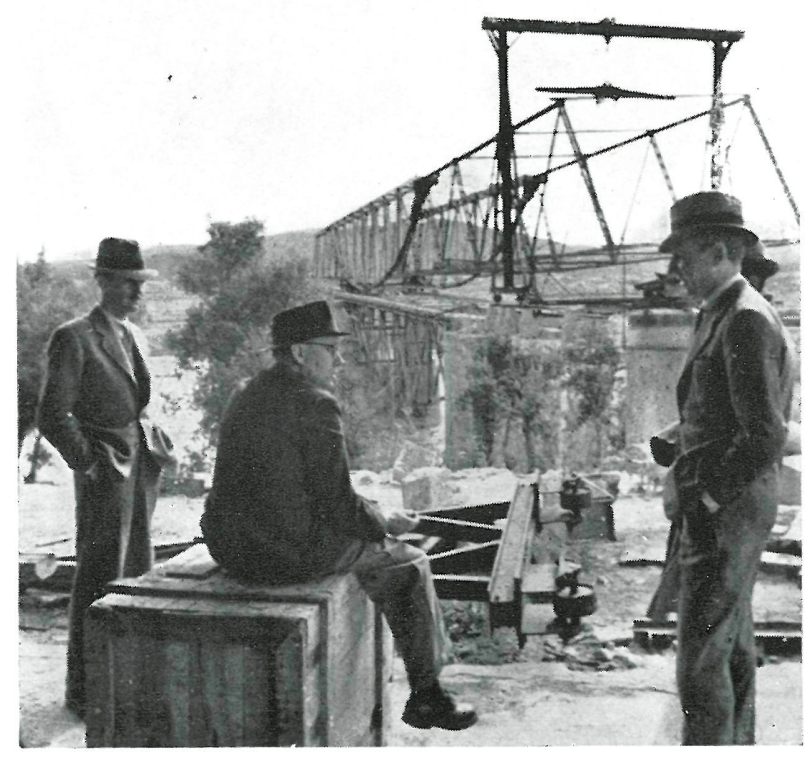

\section{puente de tordera}

emplazamiento: carretera general Barcelona - Gerona

aก̃o: 1939

ingeniero: G. ANDREU

constructor: Omes

$565 \cdot 27$

Siempr? se ha dicho que, en el hormigón armado, el hormigón está destinado a soportar las compresiones y el acero las tracciones. Este principio conduce, lógicamente, a formar las estructuras trianguladas haciendo metálicas las piezas que han de trabajar fundamentalmente a tracción, y de hormigón ligeramente armado, las encargadas de resistir, principalmente, compresiones. 

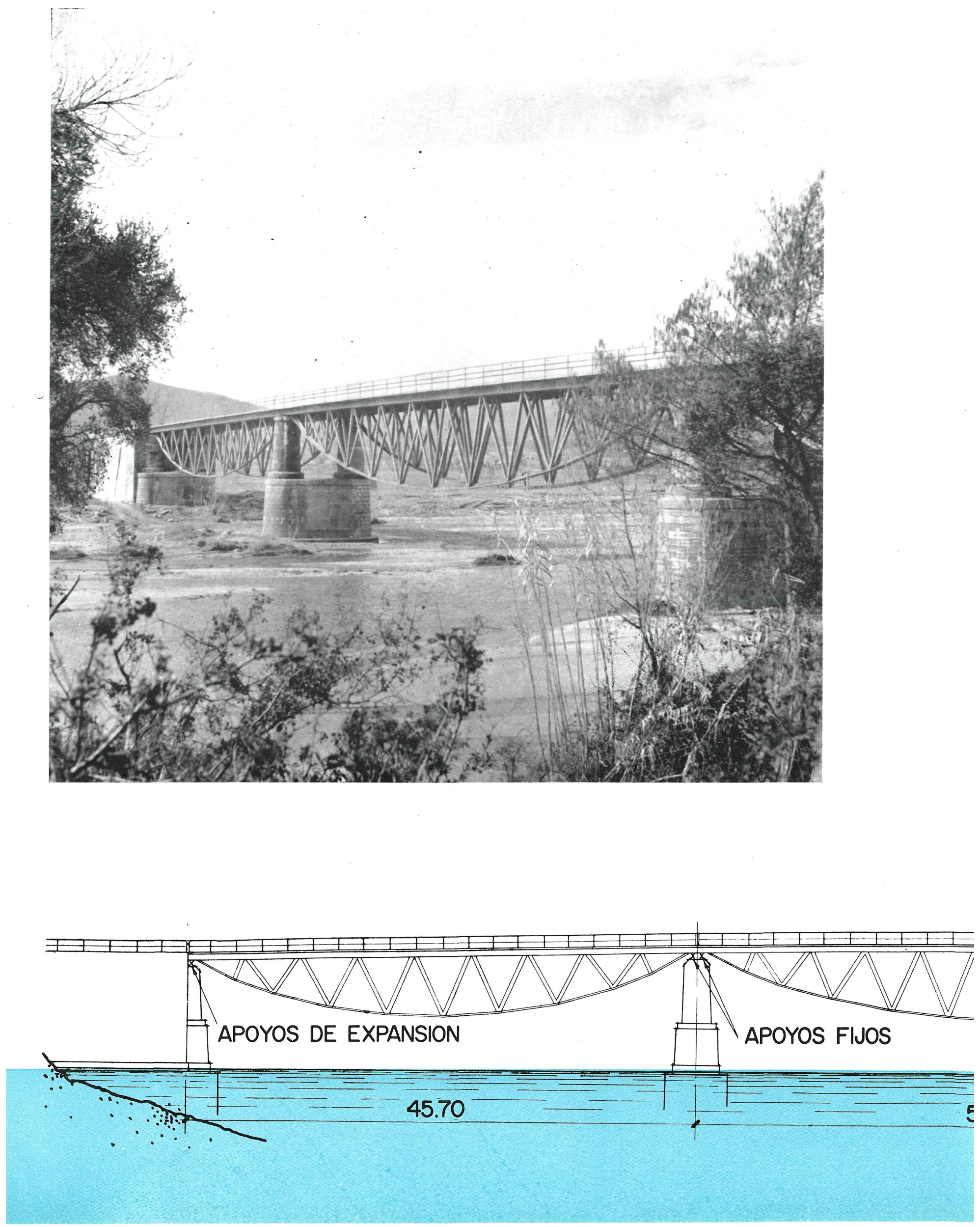


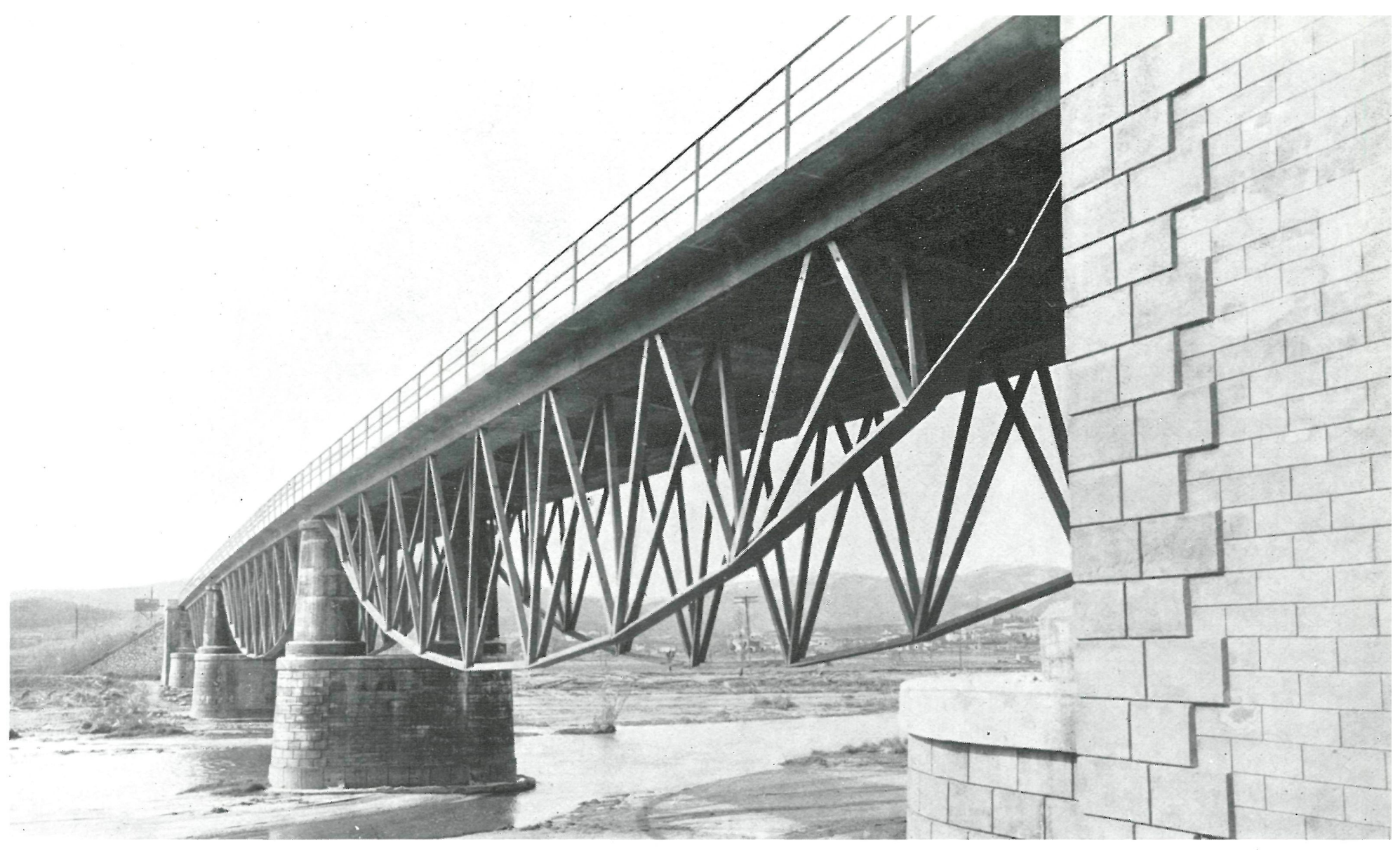

En general, el hormigón resiste las compresiones más económicamente que el acero; y, en cambio, es prácticamente incapaz de soportar tracciones. El acero se presta bien a esto último, con piezas ligeras de gran esbeltez; éstas pueden resistir también compresiones, pero en menor proporción, porque, al ser delgadas, el peligro de pandeo no les permite aceptar cargas tan fuertes como a tracción. Por consiguiente, si la proporción entre el esfuerzo de tracción y el de compresión, que han de sufrir, es la oportuna, la pieza metálica es la más indicada.

El hormigón armado no sólo no permitiría economizar acero, sino que, al aumentar el peso muerto, podría incluso aumentar la cantidad de acero requerida. En esas piezas el hormigón sólo serviría para evitar la oxidación de la armadura, pero ese papel puede desempeñarlo una buena pintura sin sobrecargar inútilmente la estructura.

Por el contrario, el hormigón, aun cuando requiere una ligera armadura para darle cuerpo y hacerlo resistente a todos los esfuerzos parásitos, de retracción, etc., es el material indicado para piezas sometidas principalmente a compresión. Su empleo está todavía más indicado cuando su presencia viene exigida por otras condiciones funcionales. Tal sucede en los pisos de puentes que requieren unas placas continuas de calzada para establecer sobre ella el material de rodadura o pavimento.

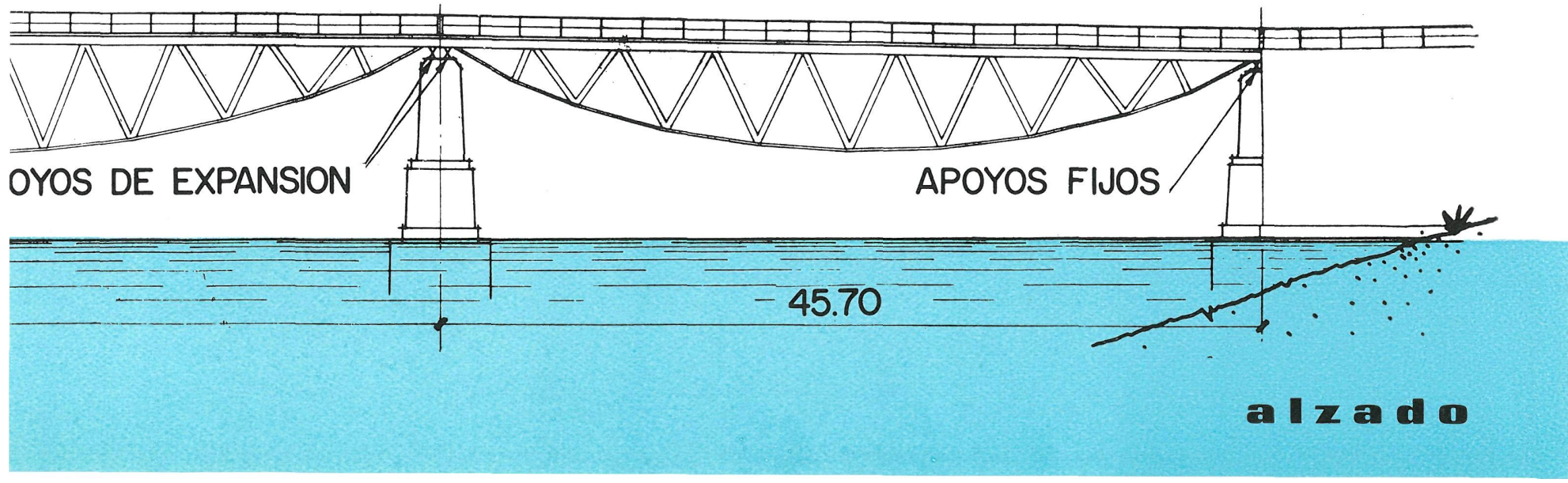



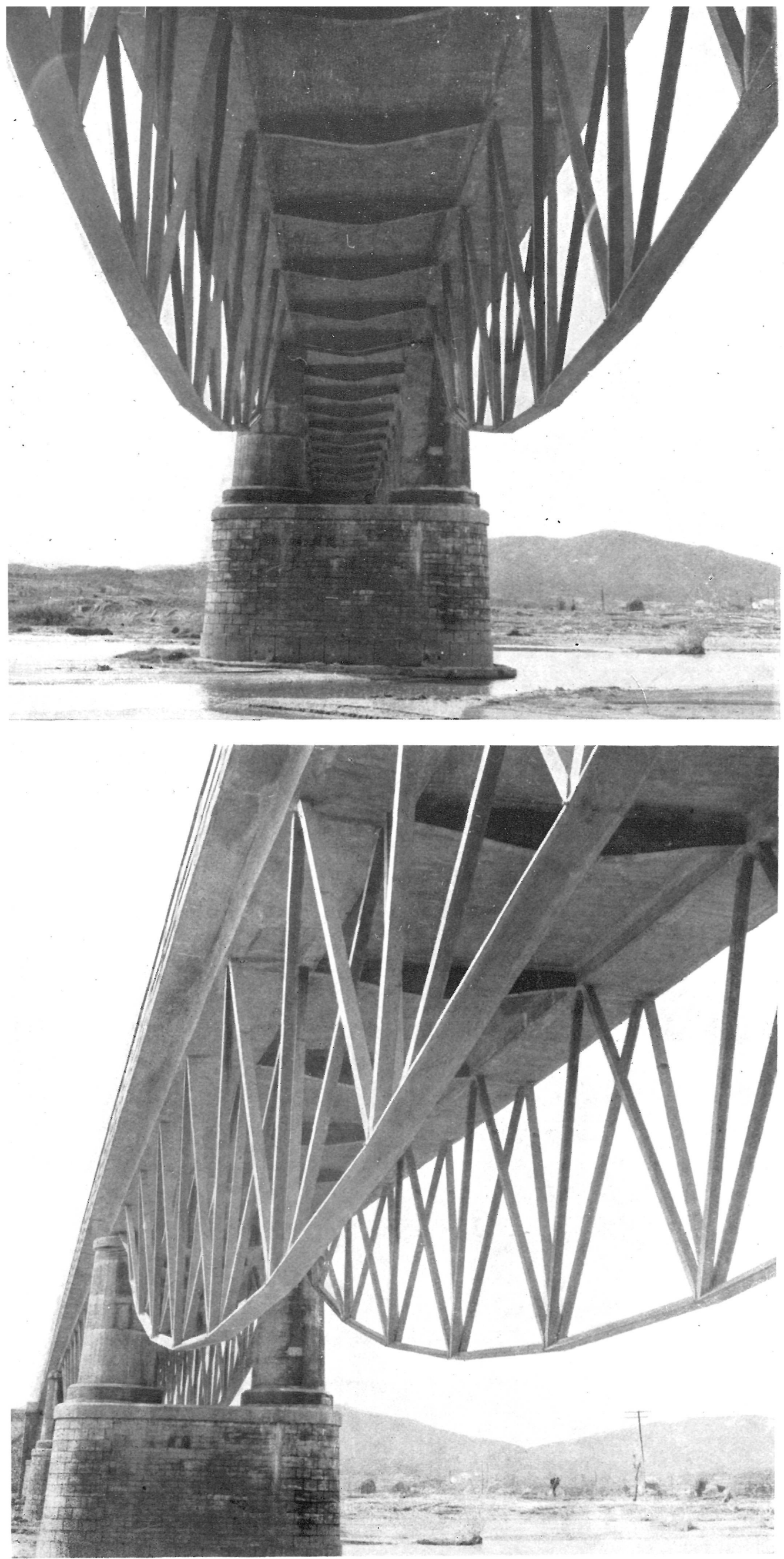

Es lógico, entonces, utilizar estos mismos elementos para que actúen como cabeza de compresión de las vigas que sostienen ese mismo pavimento, formando así la estructura del puente. Conviene, para ello, que estas vigas vayan por debajo del piso del puente.

La aplicación de estas ideas al caso del puente de Tordera condujo a la solución que se ve en las fotografías y dibujos. Era la primera vez que empleaba una estructura mixta-metálica y de hormigón armado-, para una luz relativamente importante.

La cabeza de tracción sigue un arco de elipse, elegido, tras diferentes tanteos, para lograr una tracción sensiblemente uniforme a lo largo de toda la cabeza y para tener, al mismo tiempo, una proporción entre los esfuerzos de tracción y de compresión que permitan evitar el peligro de pandeo. Las diagonales más cargadas son las extremas, cuya longitud es menor; y la sección en cajón las provee de una rigidez suficiente.

Para disminuir todo lo posible la importancia de los esfuerzos secundarios, la cabeza de tracción está formada de palastros horizontales provistos solamente de un pequeño rigidizador vertical, capaz, justamente, de soportar las flexiones debidas al peso propio entre nudo y nudo. De este modo, su gran flexibilidad evita la aparición de flexiones secundarias demasiado importantes en los arranques de las diagonales sobre esos nudos.

Este mismo deseo de disminuir los secundarios, condujo a suprimir los arriostramientos transversales corrientes entre viga y viga. Cada una de las diagonales se descompone en dos, en forma de $\mathrm{V}$, con el vértice en el nudo inferior. El empotramiento de las dos ramas de la $\mathrm{V}$ en la vigueta transversal del piso de hormigón produce el oportuno efecto de arriostramiento y deja esa vigueta en condiciones de sustentación isostática, como una viga simplemente apoyada en los planos verticales medios de cada $\mathrm{V}$.

El desarrollo de estas estructuras mixtas no ha sido posible hasta tanto que la técnica de la soldadura al arco, con electrodo revestido, ha permitido realizar enlaces suficientemente compactos para poder alojarlos dentro del hormigón sin grave perjuicio para éste. Los clásicos enlaces por cartelas roblonadas establecían planos de deslizamiento, a modo de cuchillos, demasiado peligrosos para el hormigón; y la adherencia entre ambos materiales fallaba con facilidad, ayudada por la característica tendencia a retraer que sufre el hormigón. 


\section{m in d s}
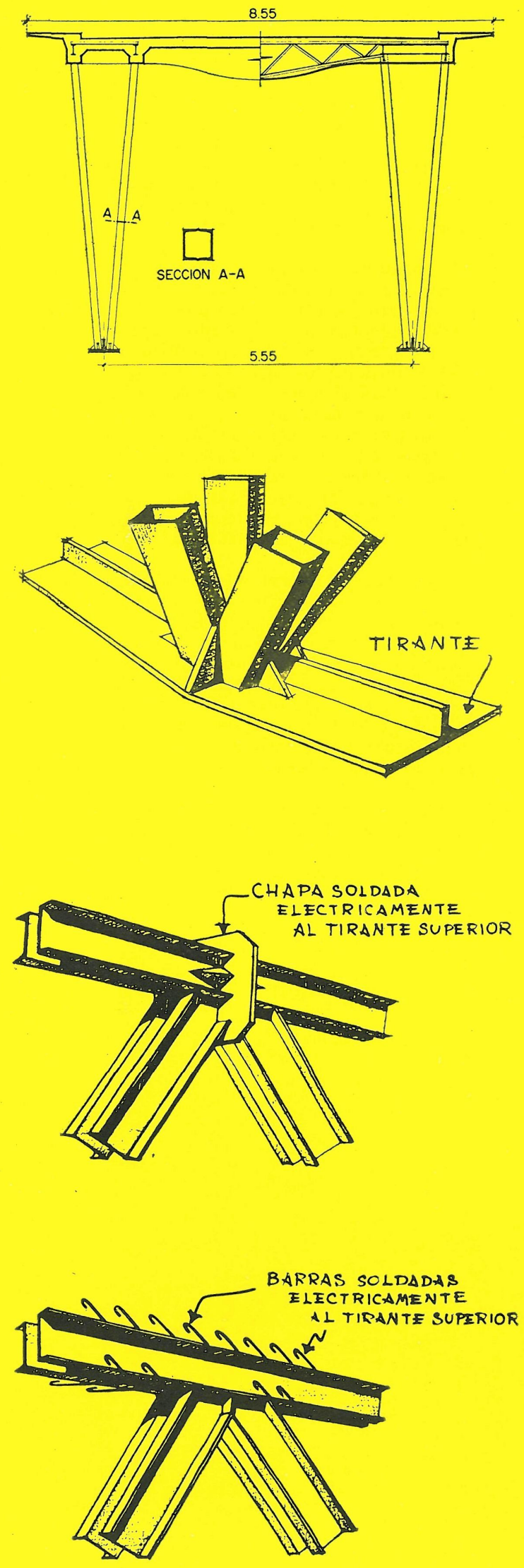

Pero hoy este defecto se evita fácilmente gracias a la libertad que la soldadura ofrece al proyectista en el diseño de sus enlaces.

El hormigón es un material menos resistente que el acero, y requiere, por tanto, tipos especiales de nudos para permitir una buena repartición del esfuerzo sobre suficiente superficie de hormigón, con una buena transmisión de las tensiones.

Esto se logra bien en el empleo de placas metálicas de asiento contra el hormigón, bien con múltiples anclajes de redondos soldados a la pieza metálica y terminados en gancho dentro del hormigón. Zunchos y rejillas pueden ayudar a éste para soportar fuertes esfuerzos locales de compresión. Pero todo esto correspondería más bien a un libro de texto que al presente tipo de exposición.

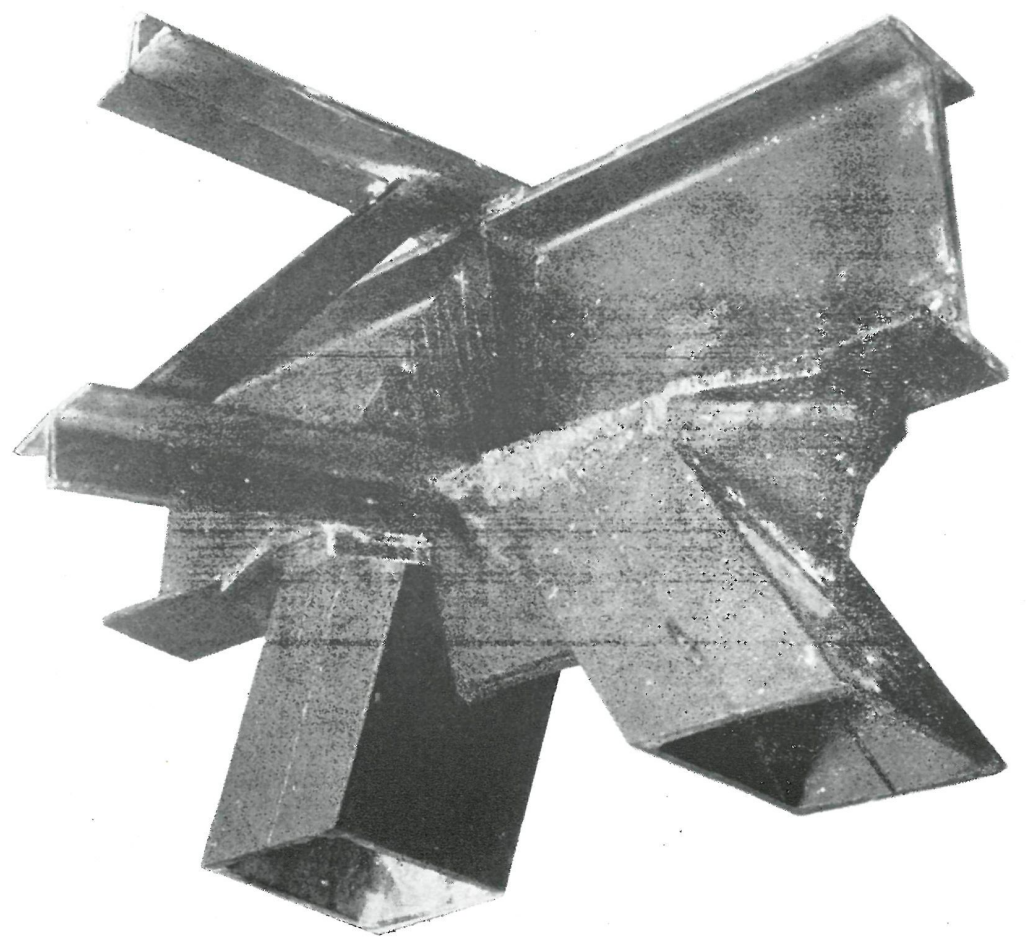

Al hacer el cálculo de los esfuerzos secundarios de este puente, se tuvo en cuenta la diferente deformabilidad de los dos materiales que forman la estructura. Para ello se consideró en el hormigón un módulo de deformación, mitad del que acusaba en un ensayo normal, con objeto de tener en cuenta las deformaciones de tipo visco-plástico (creep) que el hormigón experimenta durante los primeros meses, y aún años, cuando está sometido a compresión permanentemente. La realidad confirmó, efectivamente, un acortamiento longitudinal del piso de algunos centímetros.

Por otra parte, se consideró también la diferencia de temperatura que podía presentarse entre los elementos de hormigón armado y los metálicos que quedaban a la intemperie.

Las pruebas posteriores del puente comprobaron las previsiones. La sobrecarga de prueba se fue introduciendo lentamente, desde las ocho de la mañana hasta las dos de la tarde, mientras se hacian las medidas de las deformaciones de todos los elementos. Durante este período, el puente, en lugar de flectar hacia abajo, lo hizo continuamente hacia arriba; y la explicación es sencilla. A primera hora el sol calentaba la cabeza inferior, dilatándola. 

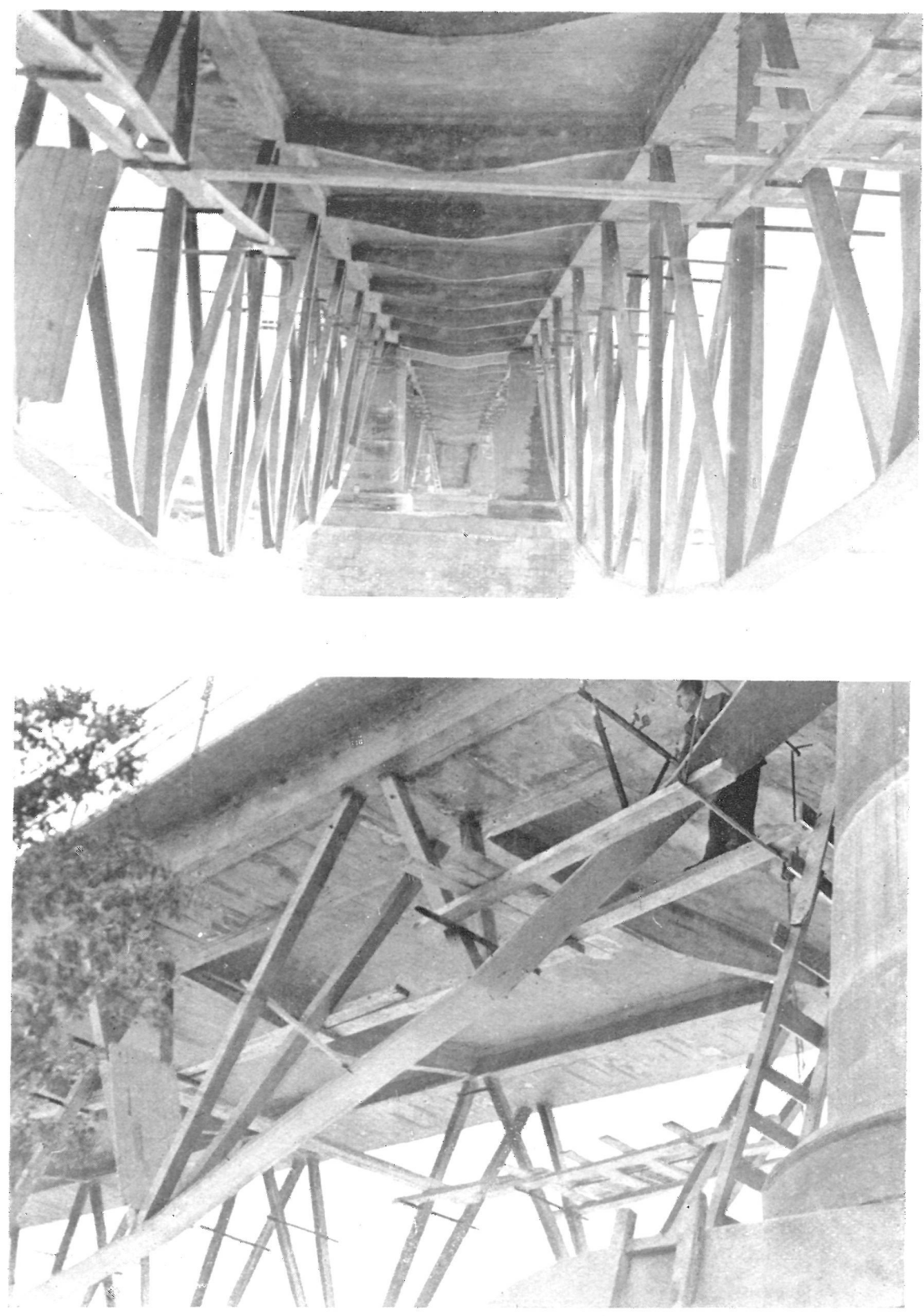

A medida que iba elevándose en el cielo, dejaba esta cabeza en sombra y elevaba la temperatura del tablero del puente que formaba la cabeza de compresión. Así, pues, ésta se iba dilatando a medida que la otra se acortaba por enfriamiento. La flecha hacia arriba producida por este fenómeno era sensiblemente mayor que la debida a las deformaciones producidas por la sobrecarga.

El primitivo puente de Tordera, cerca de Barcelona, había sido volado durante la guerra española. Quedaban las pilas, pero era necesario reconstruir los tramos: dos laterales de 45 metros de luz y uno central de 54 metros. Para dejar los fondos de las vigas a igual altura sobre el nivel de las aguas en avenida, se dio a la rasante forma parabólica, con mayor altura en el centro del puente que en las entradas; ello le proporciona, a la vez, mejor aspecto; si bien la estética no tenía demasiada mportancia, dado que, para ver lateralmente la obra, es preciso abandonar la carretera y bajar ex profeso a las orillas del río.

Las vigas llevan una ligera cabeza metálica de compresión, calculada para soportar exclusivamente los esfuerzos debidos al peso propio de la estructura metálica, y al de un primer cordón o larguero longitudinal de hormigón. Este, al reforzar esa cabeza, daba ya al conjunto la resistencia necesaria para soportar el peso del hormigón completo del tablero; y éste, a su vez, hacía posible resistir la acción de la sobrecarga rodada sobre él.

Las vigas metálicas se montaron por lanzamiento longitudinal, aun cuando la forma cur va de la cabeza inferior no es, ni con mucho, la más apropiada para ello. Su elección se debió, como antes se ha dicho, a razones de tipo mecánico.

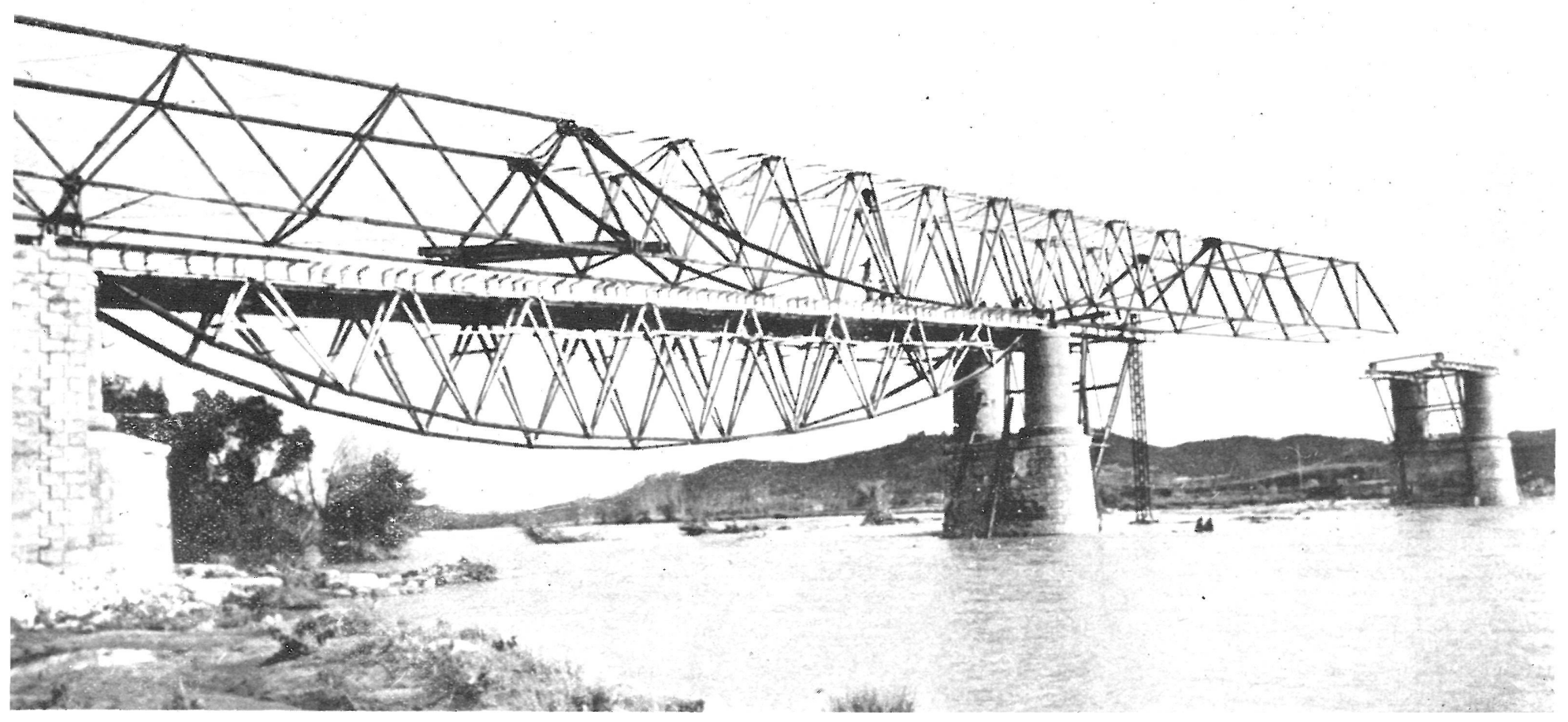

